\title{
Peranan guru PKn dalam mengatasi perilaku siswa broken home di SMP YP Mustika Padalarang
}

\author{
Eneng Martini ${ }^{a, 1^{*}}$, Crisma ${ }^{b, 2}$ \\ a Program Studi PPKn Jurusan PIPS STKIP Pasundan Cimahi, Jawa Barat \\ ${ }^{\mathrm{b}}$ SMP YP Mustika Padalarang Bandung \\ ${ }^{1}$ eneng.martini13@gmail.com \\ * korespondensi penulis
}

\begin{abstract}
ABSTRAK
Tulisan ini membahas secara kualitatif peranan dan upaya guru PKn dalam mengatasi perilaku siswa broken home di sekolah. Siswa yang kurang mendapatkan perhatian dan kasih sayang orang tua, baik karena tinggal berjauhan dengan orang tua, ditinggal menjadi TKI di luar negeri, maupun karena perceraian orang tua, cenderung memiliki sikap yang negatif. Mereka malas-malasan dalam belajar, menyendiri, agresif, bolos sekolah, menentang guru, merokok, tidak rapi, tidak disiplin waktu, bergabung dengan komunitas yang negatif. Data diperoleh melalui observasi dan wawancara kepada informan terpilih. Hasilnya menunjukkan bahwa peranan dan upaya guru PKn dalam mengatasi perilaku siswa broken home adalah dengan mengembangkan materi, metode, media, sumber dan evaluasi pembelajaran PKn yang dapat membangkitkan motivasi siswa dalam belajar. Selain itu, guru juga menjadi teladan yang baik untuk siswasiswanya.
\end{abstract}

Kata kunci: peran guru, pendidikan kewarganegaraan, perilaku siswa, broken home

\begin{abstract}
This research qualitatively discusses the role and effort of civic education teachers in handling behavior of students from broken home at school. Students who do not get enough attention and affection from their parents --either caused by living far away from their parents, being a child of Indonesian labor who works abroad, or divorcement-- tend to have negative behavior. They have no motivation to study, stand apart, show aggressive behavior, being a truant, disobey the teacher, smoking, dress not neatly, being undisciplined, and join bad communities. The data are obtained by doing observation and interview to the chosen informants. The result shows that civic education teachers do their effort to handling behavior problems of students from broken home by developing content, method, media, learning source, and evaluation of civic education to evoke their motivation in studying. As for the role, teachers try to become a good role model for their students.
\end{abstract}

Keywords: teachers role, civic education, student attitude, broken home

Copyright (C2018Universitas Ahmad Dahlan, All Right Reserved

\section{PENDAHULUAN}

Berbicara tentang pendidikan, maka berbicara pula tentang perkembangan peradaban manusia. Pendidikan berlangsung di berbagai tempat atau lingkungan baik di dalam keluarga, sekolah, maupun masyarakat dan berlangsung sepanjang hayat. Orang yang berperan dalam pembentukan pribadi siswa di lingkungan sekolah adalah guru. Guru merupakan pendidik yang memiliki peran dan tanggung jawab dalam pencapaian tujuan pendidikan. Guru pendidikan kewarganegaraan (PKn) adalah guru yang memegang peranan penting bagi siswa untuk membentuk warga negara yang baik. Pasal 1 UU No. 14 Tahun 2005 tentang Guru dan Dosen menyebut "Guru adalah pendidik profesional dengan tugas utama mendidik, mengajar, membimbing, mengarahkan, melatih, menilai dan mengevaluasi peserta didik pada pendidikan anak usia dini jalur pendidikan formal, pendidikan dasar dan pendidikan menengah". Guru adalah orang-orang yang memiliki keahlian khusus yaitu dalam bidang pendidikan yang bertugas untuk mengajar para peserta didik sesuai dengan keahliannya masing-masing dan bertanggung jawab atas kemajuan dan perkembangan peserta didik serta mengarahkan potensi yang dimiliki peserta didik.

Pembelajaran PKn memiliki karakter sebagai pendidikan karakter, sebagai pendidikan politik, dan sebagai pendidikan nilai moral. Oleh karena itu, guru PKn memiliki peranan penting dalam membentuk karakter siswa. Di samping itu, guru PKn adalah sebagai pengarah dan pembimbing peserta didik agar mereka memiliki karakter dan sikap yang mandiri, baik dan bersahaja sejalan dengan pembentukan sikap yang kritis, analisis serta pemikiran yang dinamis.

Sebagai upaya dalam pembentukan karakter, guru PKn dituntut untuk memiliki banyak usaha agar para siswa mempunyai sikap yang baik, kecerdasan yang tinggi, serta keterampilan yang bermanfaat. Dengan demikian guru PKn harus 
dapat memanfaatkan fungsinya sebagai penuntun moral, sikap dan perilaku serta memberi dorongan keras yang lebih baik (Somantri, 1976). Peran guru PKn dalam membina dan membimbing siswa agar memiliki sikap dan perilaku yang baik dapat melalui proses pembelajaran di kelas maupun di luar keas. Luasnya ruang lingkup peran dan tugas guru PKn seringkali menyebabkan fungsi pembimbingan dan pengawasan siswa menuju warga negara yang berkarakter baik tidak berjalan maksimal.

Agar tujuan pembelajaran dapat tercapai oleh siswa, guru harus mempunyai kemampuan dasar profesional dalam memberikan pengajaran kepada semua siswa. Guru dituntut untuk menguasai berbagai komponen dalam pembelajaran, yaitu meliputi materi, metode, media, sumber dan evaluasi pembelajaran. Apabila dalam proses pembelajaran di kelas seorang guru menggunakan semua komponen tersebut dengan baik, maka guru tersebut menyelesaikan tugasnya dengan optimal. Secara umum dalam prinsip-prinsip pendidikan modern sekarang ini, fungsi dan peran guru adalah sebagai pendidik, pelaksana administrasi, pemimpin, dan pengelola PBM (Rusyan, 1990).

Perilaku negatif yang seringkali dilakukan oleh siswa-siswi di lingkungan sekolah salah satunya disebabkan oleh faktor keluarga yang berantakan (broken home). Banyak anak yang telantar serta kurangnya perhatian dan kasih sayang dari orang tua sehingga anak terjerumus ke dalam kehidupan yang bebas dan melanggar norma-norma yang berlaku di masyarakat. Oleh karena itu, guru PKn sangat besar peranannya untuk mengatasi anakanak yang perilakunya tidak sesuai dengan yang diharapkan.

Hasil observasi awal di SMP YP Mustika Padalarang menunjukkan bahwa terdapat siswa yang berperilaku negatif. Sebanyak $60 \%$ permasalahan siswa di sekolah adalah diakibatkan oleh keluarga broken home (wawancara dengan guru BK). Siswa broken home dalam hal ini adalah anak yang jauh dari orang tua karena orang tua sedang bekerja di luar kota, atau bahkan di luar negeri, serta siswa yang berasal dari keluarga yang terpisah (orang tua yang bercerai), sehingga anak kurang mendapatkan perhatian serta kasih sayang dari orang tua mereka.

Pada keluarga broken home di sekolah ini, peneliti temui adanya sikap diri siswa yang kurang baik, seperti malas-malasan dalam belajar, menyendiri, agresif, bolos sekolah, menentang guru, merokok, tidak rapi, tidak disiplin waktu, bergabung dengan komunitas yang negatif. Selain itu terdapat juga beberapa siswa yang tergabung dalam komunitas luar sekolah.
Perilaku adalah respons individu terhadap suatu stimulus atau suatu tindakan yang dapat diamati dan mempunyai frekuensi spesifik, durasi dan tujuan baik disadari maupun tidak. Perilaku manusia hakikatnya adalah tindakan atau aktivitas manusia itu sendiri, antara lain berjalan, berbicara, berpakaian, tertawa, bekerja, menulis, dan sebagainya. Masa remaja ialah masa mencari identitas diri dan di dalam diri remaja terdapat keinginan besar untuk mengetahui segala sesuatu hal yang ingin diketahuinya, maka hal ini akan membuat remaja bingung dan gelisah. Perkembangan karakter anak pada masa remaja dapat dipandang telah memiliki identitas yang matang apabila sudah memiliki pemahaman dan kemampuan untuk menyesuaikan diri dengan diri sendiri, peran-perannya dalam kehidupan sosial baik itu di lingkungan keluarga, sekolah maupun masyarakat. Mengelaborasi pendapat Erikson dan James Marcia tentang identitas remaja, maka masa remaja adalah masa dimana dia bisa memilih dan menentukan jalan hidupnya sesuai dengan pilihannya atau bisa disebut dengan mencari jati diri, dimana mereka hidup dan bertahan sesuai dengan keinginannya (Yusuf LN, 2007).

Sebagai pembimbing, peran guru adalah memberikan bantuan siswa agar mampu mencapai pemahaman dan pengarahan diri yang dibutuhkan untuk melalui penyesuaian siri secara maksimal terhadap sekolah, keluarga serta masyarakat. Dalam hal ini, peran guru sebagai pembimbing merupakan dambaan setiap siswa. Tujuan penelitian ini adalah untuk mengetahui peranan guru PKn dalam mengatasi perilaku anak-anak broken home.

\section{METODE}

Pendekatan yang digunakan adalah pendekatan kualitatif, yaitu pendekatan penelitian yang dapat menghasilkan data-data deskriptif, kemudian dianalisis makna dari data tersebut. Peneliti mengumpulkan data deskriptif yang dituangkan dalam bentuk laporan, dan uraian penelitian ini tidak mengutamakan angka-angka dan statistik walaupun tidak menolak data kualitatif (Nasution, 2003). Peneliti sebagai instrumen utama berperan aktif dalam membuat rancangan penelitian, melaksanakan proses penelitian, serta menjadi faktor utama penentu dari keseluruhan proses dan hasil penelitian.

Penelitian dilaksanakan di SMP YP Mustika Padalarang Kabupaten Bandung Barat. Subjek penelitian ini adalah guru PKn, guru BK, dan lima siswa yang berasal dari keluarga broken home. Terdapat dua variabel yang diteliti, yaitu peranan guru PKn sebagai variabel bebas, dan siswa broken home sebagai variabel terikat. Data dikumpulkan 
melalui observasi, wawancara, studi dokumentasi, studi literatur, dan analisis data dilakukan melalui analisis data kualitatif.

\section{HASIL DAN PEMBAHASAN}

Kehidupan di dalam keluarga merupakan lingkungan utama yang mengawali hidup dan berkembangnya seorang anak (Savitri, Degeng, \& Akbar, 2016). Berbeda dengan keluarga broken home, peran orang tua tidak mampu hadir secara utuh dalam mewarnai pengalaman seorang anak. Anak yang berasal dari keluarga yang terpisah seringkali mengalami kegagalan emosional. Sekalipun demikian, ini tidaklah terjadi pada semua kasus broken home, sebab ditemukan beberapa contoh seorang anak dari keluarga broken home yang ketika dewasa sukses dalam hidupnya (Omoruyi, 2014).

Siswa broken home memerlukan penangan yang serius dari para guru di sekolah. Tugas guru di sekolah tidak hanya sebatas pengajar yang hanya menyampaikan materi pelajaran kepada siswa, tetapi tugas guru dalam lingkungan sekolah meliputi pula tugas mengamati, mengawasi, membimbing, mengarahkan serta mengatasi perilaku siswa, khususnya siswa broken home.

Upaya yang sudah ataupun sedang berjalan dalam mengatasi perilaku siswa broken home yang dilakukan guru PKn adalah dengan cara mengajak diskusi kepada mereka tentang masalah yang sering dialami oleh mereka dan juga guru berusaha mengawasi mereka terutama pada saat siswa berada di lingkungan sekolah, dan pada saat mereka bersosialisasi dengan lingkungan masyarakat sekitar SMP YP Mustika Padalarang.

Usaha lain yang secara rutin dilakukan untuk mengatasi perilaku siswa akibat broken home adalah dengan melakukan pendekatan kepada para siswa. Setiap satu minggu sekali, guru BK membentuk kelompok-kelompok siswa yang mempunyai masalah-masalah yang sama, program tersebut dilaksanakan di luar jam pelajaran sekolah atau setelah pulang sekolah. Kesulitan yang dihadapi guru dalam melakukan pendekatan ini adalah cara mengumpulkan siswa yang berasal dari keluarga broken home, karena tidak semua siswa terlibat dalam kegiatan tersebut. Kesulitan atau kendala tersebut diatasi dengan masuk ke kelas untuk melaksanakan pembelajaran bimbingan dan konseling. Dalam pelaksanaannya, program ini juga tidak lepas dari kerja sama antara wali kelas dan orang tua siswa/wali.

Guru PKn tidak memiliki tugas membimbing khusus siswa broken home. Namun, guru PKn memiliki andil menanamkan nilai-nilai kewarganegaraan dalam proses pembelajaran di kelas.

Nila kewarganegaraan yang dapat ditanamkan dalam pembelajaran PKn di kelas adalah ketaatan warga negara pada peraturan yang berlaku. Karena itu, guru PKn menanamkan nilai kepatuhan itu melalui pemberian nasihat, memberikan ilustrasi materi pelajaran dan menghubungkan materi pelajaran dengan contoh nyata kehidupan sehari-hari yang dekat dengan siswa. Guru PKn juga menggunakan multimetode pembelajaran, seperti metode ceramah, metode tanya jawab, metode diskusi kelompok, dan metode permainan.

Dalam konteks penggunaan media pembelajaran, guru PKn juga memutarkan film atau video yang berhubungan dengan materi, menyusun bahan tayangan dalam bentuk power point, menyusun kartu pembelajaran, gambargambar, serta memanfaatkan sumber dari media massa yang berkaitan dengan materi pelajaran.

Untuk melakukan evaluasi atau penilaian pembelajaran, guru PKn biasanya menggunakan tes tertulis dan skala sikap. Melalui skala sikap, guru PKn dapat mengetahui sikap dan perilaku semua siswa. Guru PKn tidak memberikan perlakuan khusus kepada siswa broken home, tetapi semua siswa dinilai sesuai dengan keaktifan dan hasil dari tes tertulis. Guru PKn juga selalu memberikan reward berupa pujian dan tambahan nilai kepada siswa yang aktif di kelasnya dan punishment atau hukuman berupa tugas untuk menyusun rangkuman materi di perpustakaan, kerja bakti di sekolah, atau bahkan mengurangi nilai siswa. Sumber belajar dalam pembelajaran PKn meliputi buku teks pelajaran siswa, sumber materi yang diambil dari internet dan media massa yang berhubungan dengan materi pembelajaran.

Di luar proses pembelajaran, guru PKn juga terlibat aktif dalam membina kegiatan ekstrakurikuler OSIS. Hal ini menunjukkan bahwa guru PKn harus banyak berusaha agar siswasiswanya mempunyai sikap yang baik, kecerdasan yang tinggi, serta keterampilan yang bermanfaat. Dengan demikian, guru PKn dapat memanfaatkan fungsinya sebagai penuntun moral, sikap dan perilaku serta memberi dorongan keras yang lebih baik (Somantri, 1976). Guru PKn harus dapat menuntun dan membina perilaku siswa ke arah yang lebih baik, sehingga siswa memiliki kecerdasan dan keterampilan yang dapat dilakukan melalui berbagai bidang seperti olah raga dan kesenian yang dikembangkan melalui pembinaan kegiatan ekstrakurikuler di sekolah.

Lingkungan keluarga siswa broken home merupakan tantangan cukup berat dalam mengatasi 
siswa broken home. Padahal suasana atau iklim keluarga sangat penting bagi perkembangan kepribadian anak. Seorang anak yang dibesarkan dalam lingkungan keluarga yang harmonis dan agamis, dalam arti, orang tua memberikan curahan kasih sayang, perhatian, serta bimbingan dalam kehidupan keluarga, maka perkembangan kepribadian anak tersebut cenderung positif (Yusuf LN, 2007). Adapun anak yang dibesarkan dalam lingkungan keluarga yang broken home, kurang harmonis, orang tua bersikap keras terhadap anak atau tidak memperhatikan nilai- nilai agama dalam keluarga, maka kepribadiannya cenderung akan mengalami distorsi atau mengalami kelainan dalam penyesuaian dirinya (maladjustment). Lingkungan keluargalah yang menentukan perkembangan dan perilaku anak.

Dewasa ini, generasi muda Indonesia, khususnya remaja, sedang banyak mengalami degradasi mental, moral, budaya, agama dan nilai yang menyebabkan runtuhnya moralitas generasi muda Indonesia. Oleh karena itu, orang tua dan guru perlu lebih memahami kebutuhan-kebutuhan anak. Kebutuhan-kebutuhan anak mencakup 1) kebutuhan akan kasih sayang dan keamanan; 2) kebutuhan akan pengalaman baru; 3) kebutuhan akan pujian dan pengakuan; dan 4) kebutuhan untuk bertanggung jawab (Meggitt, 2013).

Di lingkungan sekolah upaya untuk membantu perkembangan siswa broken home dihadapkan pada beberapa hambatan, antara lain kurangnya sumber referensi, penggunaan teknologi informasi dan komunikasi yang terbatas, dan tidak semua siswa mengikuti kegiatan ekstrakurikuler. Ketika melakukan penilaian pembelajaran siswa, guru PKn mengalami hambatan, diantaranya ada siswa yang membangkang dan selalu mengulangi kesalahan.

Sebagai pembimbing bagi siswanya, guru juga mempunyai peranan untuk membina, melatih, serta mengembangkan bakat yang dimiliki siswa. Karena itu, guru dituntut untuk memiliki pemahaman tentang anak yang sedang dibimbingnya. Hal ini karena akan menentukan teknik dan jenis bimbingan yang harus diberikan kepada mereka (Sanjaya, 2009). Oleh karena itu, dalam mengembangkan konsep atau materi pembelajaran, guru PKn berupaya untuk mengilustrasikan materi pelajaran dengan kehidupan nyata, dan mengaktifkan siswa atau melibatkan siswa dalam metode yang digunakan,

Proses penilaian hasil belajar siswa melibatkan bukan hanya guru PKn, tetapi juga guru BK. Kedua guru ini saling bekerja sama untuk membahas masalah yang dihadapi siswa dan mencari solusi terbaik untuk masalah tersebut. Jika sumber dan media pembelajaran tidak cukup memadai untuk melakukan pembelajaran PKn dengan baik, maka guru mencari solusinya dengan cara melakukan inovasi dan mengembangkan kreativitas guru.

Upaya lain yang dilakukan untuk mengatasi mengatasi perilaku siswa broken home di luar proses pembelajaran adalah dengan memberikan keteladanan dan menjadikan diri guru sebagai sosok yang dapat diteladani oleh siswa, memberikan motivasi dan stimulus secara terus menerus agar siswa dapat aktif dalam kegiatan pembelajaran, mengajak siswa untuk terlibat aktif dalam kegiatan ekstrakurikuler, dan memberikan teguran, peringatan serta hukuman bagi siswa yang melanggar peraturan di sekolah. Melalui berbagai upaya tersebut, siswa broken home diharapkan dapat termotivasi untuk lebih semangat dalam belajar.

\section{KESIMPULAN}

Guru PKn memiliki peran penting dalam menangani perilaku siswa broken home. Guru PKn melakukan proses pembimbingan untuk mengatasi perilaku siswa broken home baik pada saat proses pembelajaran, maupun di luar proses pembelajaran. Sekalipun tidak ada kewenangan langsung untuk mengatasi perilaku siswa broken home, tetapi guru $\mathrm{PKn}$ berperan dalam pengembangan materi, metode, media, sumber dan penilaian pembelajaran PKn yang dapat membangkitkan keasadaran siswa agar menjadi warga negara yang baik.

Hambatan yang dihadapi guru PKn dalam mengatasi perilaku siswa broken home disebabkan karena guru tidak secara langsung mengetahui perkembangan anak-anak broken home, siswa yang kurang aktif dalam mengikuti pelajaran, serta terbatasnya dukungan sarana dan prasaran pembelajaran yang memadai

Upaya yang dilakukan oleh guru PKn dalam mengatasi hambatan dalam mengatasi perilaku siswa broken home adalah melalui pemberian motivasi kepada siswa melalui pengembangan materi, metode, media, sumber dan evaluasi belajar yang inovatif dan kreatif. Selain itu, guru PKn juga memberikan contoh keteladanan yang baik di dalam kelas maupun di luar kelas.

\section{DAFTAR PUSTAKA}

Meggitt, C. (2013). Memahami perkembangan Anak. Jakarta: Indeks.

Nasution, S. (2003). Metode penelitian naturalistik kualitatif. Bandung: Tarsito. Diambil dari https://books.google.co.id/books?id=qwIrn QEACAAJ

Omoruyi, I. V. (2014). Influence of broken homes on academic performance and personality development of the adolescents in Lagos State Metropolis. European Journal of Educational and 
Development Psychology, 2(2), 10-23.

Rusyan, A. T. (1990). Profesionalisme tenaga kependidikan. Bandung: Yayasan Karya Sarjana Mandiri.

Sanjaya, W. (2009). Strategi pembelajaran berorientasi standar proses pendidikan. Jakarta: Kencana.

Savitri, D. I., Degeng, I. N. S., \& Akbar, S. (2016). Peran keluarga dan guru dalam broken home di usia sekolah dasar. Jurnal Pendidikan, 1(5), 2016.

Somantri, M. N. (1976). Metode mengajar Civics. Jakarta: Erlangga.

Yusuf LN, S. (2007). Psikologi perkembangan anak dan remaja. Bandung: Remaja Rosdakarya. 